\title{
Does One Size Fit All?
}

\section{Heterogeneity in the Valuation of Community Forestry Programs*}

\author{
Dambala Gelo $^{\dagger}$ and Steven F Koch ${ }^{\ddagger}$
}

\begin{abstract}
Through the implementation of a choice experiment valuation exercise, this study set out to identify the set of community plantation attributes that impact the welfare of potential community forestry program participants. We employed a combination of choice models to evaluate the preferences, welfare impacts and choice elasticities associated with alternative community forestry programs, allowing for different assumptions regarding heterogeneity. In line with economic theory, increased participation costs reduced the demand for community forestry, while increases in expected productivity raised the demand. With respect to preferences for the other alternatives considered: type of forest, area enclosure and type of land upon which the forest was to be situated, the results point to significant differences in preferences across the study population, suggesting that programs should be tailored to the communities in which the program is to be implemented.
\end{abstract}

Keywords: community forestry, choice experiment, conditional logit, random parameters logit and latent class model

J.E.L Classification: Q23, Q28, Q51

\footnotetext{
* We would like to thank Abebe Damte, Chitalu Chama, Alemu Mekonnen, Gauthier TshiswakaKashalala and University of Pretoria seminar participants for their helpful comments. We would also like to thank two anonymous reviewers for their contributions in improving this research. We would also like to thank Economic Research Southern Africa for their support of this research. However, all errors remain the responsibility of the authors.

${ }^{\dagger}$ PhD Candidate, Department of Economics, University of Pretoria

${ }^{\ddagger}$ Professor and HOD, Department of Economics, University of Pretoria, Private Bag X20, Hatfield 0028, Republic of South Africa, steve.koch@up.ac.za, (O) 27-12-420-5285.
} 


\section{Introduction}

Community forestry programs are expected to yield a number of direct and indirect benefits for the local community. First, by controlling, and thus reducing, the use of crop residues and animal dung for fuel, these programs are expected to increase agricultural production, partly because forests are an important source of livestocö fodder (Shylendra 2002; Jagger and Pender, 2003; Tefera et al., 2005; Babulo, 2007 and Mekuria et al., 2011). Second, by offering a substitute resource for open-access forest resources, community forests, if properly monitored, can reduce the pressure on open-access resources (Linde-Rahr, 2003). Third, community forests are often located closer to villages, such that their use is expected to unleash labour for other purposes. Fourth, the potential for an increased supply of fuel wood implies lower fuel wood prices. Finally, community forests offer environmental protection services, such as soil and water conservation, by way of reducing soil erosion and downstream siltation (Mekonnen, 2000; Shylendra 2002; Tefera et al., 2005; Babulo, 2007 and Mekuria et al., 2011).

Although there are many potential benefits, the successful implementation of community forestry programs is limited by a host of internal and external factors. External forces include decentralization reforms and market development shocks related to the village economy (Sikor, 2005). In many developing and emerging economies, community forestry programs have often arisen as the outcome of a broader decentralization process associated with promoting, public service performance and rural development (Agrawal and Ostrom, 2001; Larson and Ribot, 2004 and Ezzine-de-Blas et al., 2011). However, the decentralization of natural resources management has been plagued by state and local conflicts, to the detriment of such programs (Ezzine-de-Blas et al., 2011). Such conflicts yield incomplete property rights transfers to the local community, and, hence, incomplete decentralization of resource management attenuating local participation incentives (Larson and Ribot, 2004). In the same vein, community forestry is bound to influence market development (Sikor, 2005 and Richards, 1997). The integration of village economies into national and regional markets generates heterogeneous incentive structures among villagers and undermines collective action, which could further weaken community forest management (Ostrom, 1999). Additional research has 
outlined a set of community and resource factors affecting collective action sustainability (Ostrom, 1999 and Sikor, 2005). One such factor is group member heterogeneity; another relates to local power structures. The efforts of local elites to capture program outcomes, as described in Adhikari et al. (2004), may attenuate collective action, resulting in increased free-riding (Ostrom, 1999).

In line with the preceding concerns, Gebremedhin et al. (2003), for example, argue that community programs in Ethiopia have often failed, because the views of the community have been ignored during the design and implementation phases. Given that these programs compete for both land and monetary resources, it is in the interest of policymakers, program implementers and donors to quantify the contributions of these programs towards household welfare, and uncover evidence of the potential for such programs to positively affect rural development and protect the environment.

The quantification of household valuations of community forestry programs has proceeded along a number of lines. Köhlin and Amacher's (2005) selection model relies on revealed preference data to estimate the welfare effects of community forest plantations in terms of the value of decreased fuel wood collection times that such plantations offer. Cost Benefit Analyses (CBA), of which there are many, find that the return to community woodlots (Jagger and Pender, 2003) and area enclosures (Babulo, 2007 and Mekuria et al., 2011) are substantial in Tigray, northern Ethiopia. Mekonen (2000) and Carlsson et al. (2004) apply Contingent Valuation Methodology (CVM) to estimate willingness to pay (WTP) and examine its determinants with respect to community woodlots that are financed, managed and used by different communities in Ethiopia. Köhlin (2001), also using CVM, estimates the WTP for community forestry in Orissa, India. Similarly, Riera and Mogas (2004), Brey et al. (2007) and Wang et al. (2007) apply CVM to recreational and conservation attributes, while Qin et al. (2009) examine contractual relations, especially private property rights, associated with forestry management. Although each of these studies has provided an important contribution to our understanding of the welfare impacts of community forestry in developing countries, they are limited, because they only allow for the estimation of single attributes within multi-attribute programs (Carlsson et al., 2003). 
Such limitations, however, can be alleviated through the application of choice experiments (CE), which include multiple attributes and are, thus, capable of allowing for the estimation of the value of each of the attributes, as well as the program's welfare effects. Batsell and Louviere (1991) and Louviere (1991) have employed experiments of this nature, which are common in marketing, geography and transportation economics. Recently, these valuation methods have received more attention in environmental economics, including the valuation of wetland management and biodiversity (Boxall and Adamowicz, 2002; Carlsson et al., 2003 and Milon and Scrogin, 2006), as well as forestry (Hanley et al., 1998; Riera and Mogas, 2004, Mogas et al., 2006 and 2009; Brey et al., 2007; Wang et al., 2007 and Qin et al., 2009). However, with the exception of Arifin et al. (2009), who examine community forestry in Indonesia, there is a dearth of literature involving the valuation of community forestry program attributes that are typically relevant to peasant farm household preferences and welfare.

The motivation of the present study owes to this paucity in the literature. This study applies CE to evaluate the welfare effects of community forestry program attributes in Ethiopia, paying particular attention to peasant farmers' preferences. Importantly, community forestry is not a single attribute program; several design options are available and each of these has different benefits for different types of households, such that households are presumed to value each of the attributes differently. Therefore, we estimate WTP for selected attributes of community forest plantations that are financed, managed and used by the communities. In addition to estimating individual WTP for different attributes of a community forest, we also seek to identify sources of heterogeneity that can affect preferences. Moreover, the study provides more information than is available via standard CVM and CBA studies of community forestry plantations. It quantifies peasant trade-offs over plantation attributes, with implications for the design of community forestry interventions. It also evaluates the welfare impact of various types of forests, rather than just one type. The study also contributes to the small, but growing literature on the application of CE to evaluate environmental policy instruments in developing and emerging countries.

In this study, a combination of empirical strategies is employed, including conditional logit (CL), random parameters logit (RPL) and latent class models (LCM). These 
different strategies account for some of the limitations of standard choice models, such as Independence of Irrelevant Alternatives (IIA) in the traditional conditional logit model and restrictive parameter distribution assumptions associated with the random parameters logit model. Two major findings emerged from this study. First, the community forestry attributes considered offer substantial welfare benefits; particularly, the development of community forestry on village wastelands improves average household welfare. Second, preferences for community forestry plantations are heterogeneous amongst individuals and across groups of peasant farmers, such that community plantation interventions yield varying welfare impacts.

The remainder of this study is organized as follows. Section 2 discusses the economic and econometric framework. Section 3 describes the design of the choice experiment and data collection methods. Section 4 presents the results of the empirical analysis and Section 5 concludes and discusses policy implications generated from the study.

\section{Theoretical framework}

\subsection{Economic Model}

CEs are based on Lancaster's (1966) characteristics theory of value; a consumer's utility is a composite of the utilities for the underlying characteristics of the goods consumed. Given that environmental services contain a number of underlying characteristics, CE offers a useful representation (Hanley et al., 1998, 2001). The representation that we follow is due to Hannemann (1984) and Alpizar et al. (2001), who specify the economic model that underpins the behavioral aspects of our choice experiment. Therefore, we assume that our peasants maximize utility by choosing the program $i \in\{1, \ldots, N\}$ with the greatest attribute benefit, subject to its cost, outlined in (1) and (2).

$$
\begin{gathered}
\max _{\delta} U\left[\delta_{1} c_{1}\left(A_{1}\right), \ldots, \delta_{N} c_{N}\left(A_{N}\right), z\right] \\
y=\sum_{i=1}^{N} \delta_{i} p_{i}+z
\end{gathered}
$$

subject to:

$$
\begin{gathered}
\delta_{i} \delta_{j}=0, \forall i \neq j \\
z \geq 0, \delta_{i}=\{0,1\} \forall i
\end{gathered}
$$


In equations (1) and (2), $U[\cdot]$ is a quasi-concave utility function; $c_{i}\left(A_{i}\right)$ is the composite of alternative $i$, which is a function of generic and alternative specific attributes, given by the vector $A_{i}$; $\delta_{i}$ is a binary indicator equal to one if alternative $i$ is chosen; $p_{i}$ is the cost of the alternative; $y$ is income and $z$ is the composite bundle of ordinary goods with its price normalized to unity, and its value is equal to income net of the cost of the chosen alternative. Therefore, $z=y-p_{k}$, if alternative $k$ is chosen. Other important properties that follow from (1) are: $U_{j}=0$ if $\delta_{j}=0$ (where $U_{j}$ is the marginal utility of choice $j)$, and $V_{k}\left(A_{k}, y, p_{k}\right)=U\left[c_{k}\left(A_{k}\right), y-p_{k}\right]$ is the indirect utility of the chosen alternative (Alpizar et al., 2001). An individual chooses alternative $k$, if the indirect utility associated with choice $k$ exceeds the indirect utility of any other alternative.

$$
V_{k}\left(A_{k}, y, p_{k}\right) \geq V_{j}\left(A_{j}, y, p_{j}\right), \forall k \neq j
$$

In what follows, we derive a number of econometric specifications that can be derived from equation (3) with respect to our CE study.

\subsection{Econometric Specification}

In CE field settings, individual choices aren't completely deterministic, as suggested by (3); instead, choices are affected by alternatives that are not included in the experiment and by other unobservable individual characteristics (Hannemann and Kanninen, 1996). McFadden (1974) made use of this intuition in developing the random utility model, which was accomplished through the inclusion of an error term in (3).

$$
V_{k}\left(A_{k}, y, p_{k} ; \varepsilon_{k}\right) \geq V_{j}\left(A_{j}, y, p_{j} ; \varepsilon_{j}\right), \forall k \neq j
$$

For simplicity, the indirect utility function is assumed to follow a standard linear-inparameters function of the observables, appended to which is a type I extreme value error term. This functional specification leads to a conditional logit model, which is often used to model discrete choice behavior under the random utility framework (Train, 1998 and Greene and Hensher, 2003). However, CL is underpinned by IIA, and, therefore, fails to account for unobserved heterogeneity and potential correlation between available choices. Given this limitation, more flexible approaches are desirable. One such extension is the RPL; another is the LCM. In this study, in 
addition to the base CL methodology, we apply both RPL and LCM to analyze preferences related to the establishment of community forestry programs. The RPL generalizes the CL by allowing coefficients to vary randomly over individuals (Train, 1998), and, therefore, the model relaxes IIA and can represent any substitution pattern. Furthermore, the RPL explicitly accounts for unobserved heterogeneity (Train, 1998; Carlsson et al., 2003). The LCM, on the other hand, allows coefficients to vary across subgroups of the population and also relaxes IIA.

In our model, we assume a linear-in-parameters specification for indirect utility, where we denote the individual with subscript $q$, the choice with $i$, and the choice set with $t^{1}$

$$
V_{i q t}=\alpha_{i q}+\gamma_{i} s_{q}+\beta_{q} x_{i q t}+\varepsilon_{i q t}
$$

In (5), $\alpha_{i q}$ is the individual alternative-specific intercept that captures the intrinsic preference for the alternative, $\gamma_{i}$ captures systematic preference heterogeneity related to socioeconomic characteristics, where $s_{q}$ is a vector of socio-economic characteristics; $\beta_{q}$ captures systematic preference heterogeneity related to program attributes, $x_{i q t}$ is the vector of attributes (including costs) for alternative $i$ and $\varepsilon_{i q t}$ is stochastic accounting for observational deficiencies, due to unobservable components in the model that are assumed to be uncorrelated with the observed components.

\subsubsection{Conditional Logit}

In general, (5) is a logit model with both alternative-varying and alternative-invariant regressors. As such, it constitutes a mixed logit model. However, following the literature, we restrict $\gamma_{i}=\gamma$ and $\alpha_{i q}=\alpha$, since the real interest is in attribute preferences, rather than alternative-specific effects. ${ }^{2}$ Assuming $\beta_{q}=\beta$ and that each of the errors is identically and independently distributed (IID) type 1 extreme value, a CL can be estimated based on the following probability model.

$$
P_{q}(i)=\frac{\exp \left(\beta x_{i q t}+\alpha+\gamma s_{q}\right)}{\sum_{l=1}^{N} \exp \left(\beta x_{l q t}+\alpha+\gamma s_{q}\right)}
$$

Estimation can proceed with data that is pooled over all of the choice experiments.

\footnotetext{
${ }^{1}$ In the choice experiment, each individual is asked to choose amongst three different alternatives on four separate occasions; therefore, we observe each individual four different times.

${ }^{2}$ A more general model allowing for alternative-specific effects has been estimated, but is not reported here. Importantly, the alternative-specific effects do not change the underlying conclusions.
} 


\subsubsection{Random Parameters Logit}

The RPL, on the other hand, extends the CL, by allowing the coefficient vector $\beta_{q}$, to vary across the population according to the density $f(\beta \mid \theta)$, where $\theta$ is a vector of the parameters of the distribution, while the CL assumes that the preceding density is degenerate. Assuming the error terms are IID type 1 extreme value, an RPL (Train, 1998) can be specified. Following Carlsson et al. (2003), the conditional probability of alternative $i$ for individual $q$ in choice situation $t$ can be specified.

$$
P_{q}\left(i t \mid s_{q}, x_{i q t}, \beta_{q}\right)=\frac{\exp \left(\beta_{q} x_{i q t}+\alpha+\gamma s_{q}\right)}{\sum_{l=1}^{N} \exp \left(\beta_{q} x_{l q t}+\alpha+\gamma s_{q}\right)}
$$

One of the maintained assumptions in the RPL inherent in (6) is that individual utilities vary, but are stable across the different choice experiments (Train, 1999).

Given (6), the conditional probability of observing a sequence of choices is simply the product of the individual choice probabilities for each choice set. Denoting $j(q, t)$ as the sequence of choices from all of the experiments, the conditional probability can be written, as in (7).

$$
\pi_{q}\left(j(q, t) \mid s_{q}, x_{i q t}, \beta_{q}\right)=\prod_{t=1}^{T} P_{q}\left(i t \mid s_{q}, x_{i q t}, \beta_{q}\right)
$$

Due to the variation in the $\beta_{q}$ parameter vector, the preceding conditional probability needs to be integrated over the assumed density, in order to arrive at the unconditional probability in (8).

$$
P_{q}\left(\theta \mid s_{q}, x_{i q t}\right)=\int \pi_{q}\left(j(q, t) \mid s_{q}, x_{i q t}, \beta_{q}\right) f(\beta \mid \theta) d \beta
$$

However, the integral in (8) does not have an exact solution. Therefore, we estimate via simulated maximum likelihood (Revelt and Train, 1998; Train, 1999). Furthermore, it is assumed that there is correlation between the randomly distributed parameters, and, therefore, we estimate the full variance-covariance matrix of the parameter vector, $\Sigma_{\beta}$, assuming a normal distribution, i.e., $\beta_{q} \sim N\left(\bar{\beta}, \Sigma_{\beta}\right)$. Given the Cholesky decomposition of the variance-covariance matrix, $\beta_{q}=\bar{\beta}+C \eta_{q}$, where $\eta_{q}$ is a vector of standard normals. In other words, we estimate both $\bar{\beta}$ and $C$, such that $C C^{\prime}=\Sigma_{\beta}$. 
Despite the desirable properties of RPL, allowing for individual heterogeneity and correlation across alternatives, it is subject to restrictive assumptions. In this case, those assumptions are based on the assumed distribution of the coefficient vector. The two most common are: (a) the log-normal distribution and (b) the normal distribution. However, there is no rule of thumb to select the distribution. As with any sort of model misspecification, the estimated results could be biased if the distribution is misspecified (Carlsson et al., 2003). ${ }^{3}$

\subsubsection{Latent Class Models}

One way to resolve the aforementioned problem associated with the potential misspecification of the underlying parameter distribution is to avoid, as much as possible, distributional assumptions, relying, instead on either non-parametric or semi-parametric methods. The LCM, which is semi-parametric, offers one such avenue. The LCM largely resembles the RPL by allowing for preference heterogeneity, although the heterogeneity is modeled as discrete parameter variation (Greene and Hensher, 2003), rather than continuous variation. Instead, individuals are sorted into classes or segments of the population, which are not observed by the analyst.

Assuming that there exists $R$ segments in the study population, and that an individual belongs to segment $r \in\{1,2, \ldots, R\}$, the utility function in (5) can be re-specified to account for segmentation.

$$
V_{i q t \mid r}=\alpha_{i q \mid r}+\gamma_{i \mid r} S_{q \mid r}+\beta_{q \mid r} x_{i q t \mid r}+\varepsilon_{i q t \mid r}
$$

Utility parameters are, thus, segment specific (Boxall and Adamowicz, 2002). Maintaining the parameter restrictions applied in the CL model, and assuming that $\mu_{r}$ represents a segment-specific mean, the segment-specific choice probability restates (6).

$$
P_{q \mid r}(i)=\frac{\exp \left(\mu_{r}\left(\beta_{r} x_{i q t \mid r}+\alpha_{r}+\gamma_{r} s_{q \mid r}\right)\right)}{\sum_{l=1}^{R} \exp \left(\mu_{l}\left(\beta_{l} x_{i q t \mid l}+\alpha_{l}+\gamma_{l} s_{q \mid l}\right)\right)}
$$

Following Swait (1994), we define the probability that an individual $q$ is in segment $r$ as given by an additional multinomial logit probability.

\footnotetext{
${ }^{3}$ Ferrini and Scarpa (2007) undertake a Monte Carlo study of the effects of some aspects of misspecification; however, they focus primarily on CL and nested logits applied in CE studies.
} 


$$
\Lambda_{q r}=\frac{\exp \left(\tau \rho_{r} s_{q}\right)}{\sum_{l=1}^{R} \exp \left(\tau \rho_{l} s_{q}\right)}
$$

In (11), $s_{q}$, as before, is a vector of socio-economic variables, $\rho_{r}$ is a vector of parameters and $\tau$ is a scale factor. Therefore, the joint probability that a randomly chosen individual $q$ chooses alternative $i$ and is in segment $r$ is given by the multiplication of the probabilities in (10) and (11).

$$
P_{q}(i)=\sum_{r=1}^{R} \Lambda_{q r} P_{q \mid r}(i)
$$

\section{Experimental Design and Survey Data}

\subsection{Experimental Design}

This study presents the results of a valuation exercise, using CE to elicit household perceptions of the welfare effects of potential community forestry programs in selected sites in Ethiopia. The Ethiopian Federal Ministry of Agriculture in collaboration with World Bank previously selected our study sites for possible intervention, due to high levels of deforestation and increased demand for woody biomass in these areas (World Bank, 2008). Within these sites, we administered a CE survey on a sample of 600 randomly selected heads of households, in which respondents were asked to choose their preferred option from a choice set containing the status quo and two alternative scenarios with different levels of community forest improvements. Each respondent was asked to provide answers across four different choice sets, yielding a total of 2400 observations. Community forestry alternatives were constructed in a way that the respondent is forced to make trade-offs. To this effect, the experimental design removes dominant choice sets in which one alternative is strictly better than another, since little would be learned from such choices. ${ }^{4}$ The $\mathrm{CE}$ questions were designed around four attributes of community forestry: tree species mix, type of place for plantation of the woodlot, the wood harvest quota and the cost to the participant.

Although CE has some desirable properties, compared to CVM, such as the reduction of some of the potential biases found within CVM, as well as allowing for the

\footnotetext{
${ }^{4}$ For detailed design principles of choice experiments, see Huber and Zwerina (1996).
} 
possibility of testing for internal consistency (Adamowicz et al., 1998 and Alpizar et al. 2001), CE is not a panacea. Appropriate CE methods require careful design, selection of the attributes, the attribute levels and the choice contexts. Furthermore, careful survey design, implementation and appropriate sampling methods are required to guarantee the best results. Therefore, the CE methodology was underpinned by a meta-analysis of the literature; a pilot study of the methodology was also undertaken to determine if the potential participants understood the survey.

Initially, determination of the appropriate plantation attributes and their levels was considered, after examining EFAP (1993), Mekonen (1999, 2000), Shylendra (2002), Jaggar and Pender (2003), Gebremedhin et al. (2003) and Babulo (2007). The preceding research identified area enclosures, multipurpose trees and eucalyptus plantations as the major forest types used for private woodlots and community plantations across Ethiopian farming communities. Moreover, this research provided estimates of the approximate annual demand for household fuel wood consumption. To obtain additional and complementary information, we consulted researchers specializing in community forestry, including experts from the Wondo-Genet College of Forestry and the Awassa College of Agriculture at Hawassa University. Finally, we conducted focus group discussions. The combination of these processes helped determine a wider range of attributes and their levels. We then chose attributes that are more important for both farmers and policymakers; our choices are described in Appendix A. The attributes and levels were used to create choice sets using the orthogonal main-effect design in SAS, which results in 24 different choice sets blocked into four combinations of three, based on the D-optimal criterion (Kuhfeld, 2001).

Once the CE had been developed, a pilot study was conducted to determine if the survey population could be reasonably expected to cope with four different sets containing three potential choices each. The pilot survey, conducted across 60 household heads revealed no problems, and, therefore, we proceeded. Within the survey, households were randomly assigned to one version of the questionnaire, comprising of four choices sets; consult Appendix B for an example of one version of the questionnaire. Before proceeding with the questionnaire, the purpose of establishing a community forest was briefly explained. In order to make the scenario 
as realistic as possible, a suitable area of land within each study site was identified and its size specified; respondents were told that a community forest could be established on that site. Subsequently, respondents were told that we were interested in their views regarding the options that were available for that community forest, and the attributes used in the choice experiment were explained. Each respondent was provided with a separate fact-sheet describing the attributes and their levels. The fact sheet contained pictures illustrating the levels of the attributes in the choice sets, and these illustrations were verbally described. Pictorial and verbal descriptions are especially useful, considering the literacy levels of most rural Ethiopians.

In each choice set, respondents were asked to choose their preferred option. The choice set always included the status quo - the base alternative - in which a community plantation would not be established and there would be no cost implication, as well as two alternatives containing differing community plantation attributes. Each alternative is identified by the tree species (namely: eucalyptus, multipurpose trees and a mixture of the two) or area enclosure. For every choice set there corresponded two alterative forest types. The entire CE survey, thus, involved choosing between the following combinations; eucalyptus versus multipurpose forest, eucalyptus versus mixed species, eucalyptus versus area enclosure, multipurpose forest versus mixed species forest, multipurpose forest versus area enclosure and mixed species forest versus area enclosure. The forest type could be the same between two or more choice sets, although the level of other attributes would be different. ${ }^{5}$ Although respondents were not specifically asked whether or not they would be willing to participate in a community forestry program, the proportion of respondents always choosing the status quo provides some information related to protest votes and non-participation. In addition to preference elicitation questions, we also interviewed the same respondents to elicit data on socio-economic variables. Moreover, data on the density of existing forest cover was obtained from a spatial GIS survey.

\subsection{Description of the Data}

\footnotetext{
${ }^{5}$ For example, in the choice set presented in Appendix B, the respondents must choose between an area enclosure and a multipurpose forest, wherein the former represents alternative 1 and the latter represents alternative 2. The first alternative yields 15 loads for each household annually, is to be established on degraded land and requires a contribution of Ethiopian Birr (ETB) 30 from each household. The second alternative, on the other hand, yields 30 loads annually for each household, is established on productive grazing land and requires a contribution of ETB 30 from each household.
} 
The socio-economic data used in the empirical analysis is described in Table 1. Although the primary purpose of the analysis is to examine preferences for various types of community forests, it is expected that individual, household and community level characteristics are likely to affect the demand for various community forest attributes. Therefore, the survey collected information on the gender of the household head, household livestock holdings (in TLUs, 1 TLU=250kg), household size, the age of the household head, the education of the household head and a measure of household access to alternative forests, including natural forests, private woodlots or community plantations. Our measure of access to alternative sources of forests products and services is the per-hectare biomass per-capita, obtained from GIS data.

We expect that increased access to alternative forests will tend to reduce the demand for community forestry attributes, because alternative forests can serve as a substitute for community forestry. Similarly, we expect that increased wealth, in terms of livestock, is negatively associated with community plantation participation, and, therefore, community plantation attributes, because community plantations demand greater labour contributions. Since wealthy households have higher opportunity costs for labour, it is relatively costly for wealthy households to participate in community plantations. A similar expectation holds for the household head's level of education. For the remainder of the variables, we do not have any a priori expectations.

\section{Empirical Results}

As outlined in Section 2, we estimated the utility function parameters $\beta_{q}$ using CL, RPL and LCM. In all models, a common intercept and common socio-economic effects across the alternatives were included. Furthermore, preferences were assumed to be stable across the alternatives, although in the RPL and LCM, preferences were assumed to be heterogeneous. We assumed all attributes in the RPL were normally distributed, with the exception of the cost. The cost parameter was assumed fixed for two reasons: (a) the distribution of the marginal willingness to pay for an attribute is the same as the distribution of that attribute's coefficient - in other words, allowing costs to be randomly distributed creates unnecessary complications - and (b) we wish to restrict the cost effect to be non-positive for all individuals (Carlsson et al., 2003 
and Phanikumar and Maitra, 2006).

\subsection{Utility Parameter Estimates}

The results from the empirical analyses are presented in Table 2. As expected, and the reason for considering multiple models, the utility parameter estimates are quite different across the three models. In terms of comparing the models, the CL is nested within the RPL, and the RPL is statistically preferred to the CL at the 0.001 significance level $\left(2 \Delta \ell=76.36>\chi_{6, .001}^{2}=22.45\right)$, where $\ell$ refers to the estimated log-likelihood. The significant result is partly due to the degree of correlation between the attribute coefficients (presented in Appendix Table C.1). Furthermore, the RPL results imply significant preference heterogeneity, as the estimated standard deviations for both Eucalyptus plantation and area enclosure attributes are significant.

In terms of the LCM, estimates are presented for three segments of the population, as the Bayesian Information Criterion selected three segments. It is also possible to compare the CL and the LCM, since the CL is nested within the LCM; in terms of the comparison, the LCM is statistically preferred to the CL at the 0.001 level of significance $\left(2 \Delta \ell=172.1>\chi_{24, .001}^{2}=51.18\right)$. The difference between the LCM and CL is driven, at least in part, by the statistically significant class probabilities, which attest to the presence of discrete preference heterogeneity. However, the RPL is not nested within the LCM, and, therefore, no comparison test is available for these two models.

Given the estimated preference heterogeneity in the RPL and across population segments in the LCM, as well as the statistical significance of both the RPL and the LCM over the CL, we are led to prefer the models that allow for heterogeneity. Regardless of which model is considered, the estimated effect of cost is negative, which is line with economic theory; as costs rise, demand falls. However, the estimated cost coefficient is only significant for the CL, and for segments two and three in the LCM. For the rest of the attributes, preferences for all of the attributes are positive and significant in the CL, while all attributes, except for the Eucalyptus plantation, yield positive and significant preference coefficients. However, the RPL offers more information, as the estimates imply that preferences for both Eucalyptus plantations and area enclosures are heterogeneous amongst the survey respondents. 
Although the estimated coefficients for the attributes in each of the segments are not similar, the LCM agrees with the RPL results in supporting significant preference heterogeneity. Interestingly, survey respondents in segment two have a preference for the location of the plantation (on degraded land), while Eucalyptus plantations, multipurpose tree plantations and area enclosure are strictly not preferred. For segment three, Eucalyptus forests and multi-purpose trees are also not preferred, while harvesting quotas and plantation location (on degraded land) are strictly preferred. Segment one is distinct in that this segment of the population is indifferent, in a statistical sense, to each of the attributes considered in the CE.

Although Eucalyptus is commonly observed in the Ethiopian rural landscape, the observed variation in preferences could arise from the following factors. First, fuel wood and poles from Eucalyptus are mainly sold, although Eucalyptus is also used for farm implements and dwelling construction. If farmers are not well integrated into markets for the sale and purchase of Eucalyptus poles, and other forests are available for farm implement production and construction purposes, farmers are less likely to view Eucalyptus as a favourable community forest alternative. Second, there is a common view amongst farmers, policymakers and agricultural experts in Ethiopia that Eucalyptus degrades land allocated to its plantation (Jagger and Pender, 2003). Therefore agricultural experts and rural development workers could easily influence farmers, affecting their preferences. Our results lend support to Mekonnen (2000), who found that the WTP for Eucalyptus community woodlots varied across study villages in Ethiopia.

With respect to area enclosures, ${ }^{6}$ the CL and RPL parameter estimates suggest that farmers prefer area enclosures to be part of the community forestry program. However, the RPL results further indicate that preferences for this form of forestry are heterogonous amongst farmers, a conclusion that is supported by the wide variation in LCM estimates across classes. Specifically, segment two respondents strictly do not prefer area enclosures, while segment one and segment three respondents are

\footnotetext{
${ }^{6}$ In survey questionnaire, area enclosure is described as restricting human use of grazing area notably hilly sides until its vegetation (trees and grass) sufficiently regenerate for use. The village community set a side such area and fences and guard against encroachment. At latter stage, the wood and grass products are harvested and shared among community members owing to the rule set by the council of community.
} 
indifferent. The heterogeneity that is observed in relation to area enclosures is likely to be related to study site variation, in terms of land use and agro-ecology. Area enclosure interventions are limited to woodlands, wherein semi-dry and dry agroecology can reclaim wasteland and/or improve grass and woody biomass production, according to Tefera et al. (2005) and Mekuria et al. (2010). Open grazing on communal land is typically associated with semi-dry and dry agro-ecology, and therefore, households in those sorts of areas, because they depend on grazing activities, may not prefer area enclosures, as we have found.

Finally, we turn to the socio-economic variables that were included in the analysis. ${ }^{7}$ As expected, our alternative forest access measure significantly reduces the demand for community forestry in the CL and the RPL. However, there was significant heterogeneity in the estimates across the LCM; segment two's demand increased, while segment three's demand decreased. There is also significant heterogeneity in preferences related to livestock ownership; it is a significant and positive determinant of community forestry demand amongst segment two respondents. Recalling that segment two also had a strong preference for forests on degraded land, the estimates related to forest density and livestock ownership support the contention that grazing needs are an important component of community forest preferences, i.e., farmers with more livestock are concerned that the community forest may compete with grazing land, which is the major source of livestock feed in rural Ethiopia. Finally, the sex of the household head does not follow a constant pattern. Male household heads have reduced demand for community forestry in the CL and segment two of the LCM, but increased demand in the RPL and in segment three of the LCM.

\subsection{Welfare Measures}

The preceding coefficient estimates, although interesting, are not easily interpreted, due to the differences in the estimation models and the scale factor associated with these values (Greene and Hensher, 2003). In order to improve interpretability, marginal rates of substitution between the attributes were computed, using the negative of the cost coefficient as the denominator. The distribution of these ratios is

\footnotetext{
${ }^{7}$ Household size, the education of the household head and the age of the household head were not included in the analysis. When included, the variance-covariance matrix became singular; further, when included separately, no statistically significant effects were observed.
} 
obtained via the Krinsky-Robb (Krinsky and Robb, 1986) method. ${ }^{8}$ These ratios can be interpreted as the average marginal WTP for a change in each attribute (Hannemann, 1984; Train, 1998; Carlsson et al., 2003 and Greene and Hensher, 2003). The calculated marginal rates of substitution between the attributes are presented in Table 3.

Compensating-variation welfare estimates, the willingness-to-pay, from both the CL and the RPL models, show that all of the choice attributes offer a positive welfare gain, as expected from the positive utility parameter estimates. In each of these models, the average welfare gain from area enclosure community forestry is the largest, followed by multipurpose community forestry, while harvest quotas provide the smallest welfare gain; the ranks for the remaining attributes vary by model. Furthermore, the average WTP is larger for the RPL model than the CL model.

As expected, given the differences in utility parameter estimates across segments in the LCM, the average marginal WTP varies widely across the segments. However, the estimates are more precise. Average WTP estimates are positive for nearly all attributes in segment one, with the exception of plantations on degraded land, but all are smaller than for either the CL or RPL estimates. On the other hand, segment two estimates for Eucalyptus, multipurpose forests, area enclosures and harvest quotas are negative, while mixed species forests and plantations on degraded land all have positive WTP averages. These results suggest that a community forest established on grazing land is a welfare increasing option for this group. It further implies that this group is not concerned with grazing land shortages. Otherwise, they may feel that a community forest established on wasteland is not relatively productive.

One feature, however, generally arises from the results: area enclosures offer the highest average welfare among the study participants, when segment two of the LCM is ignored. Babulo (2007) notes that, in addition to on-site production of wood and grass, area enclosures provide significant off-site services, such as downstream soil erosion reduction and decreased damage in reservoir storage volume and, thus, greater water supplies. Cost-benefit analysis studies by Babulo (2007) and Mekuria et al.

\footnotetext{
${ }^{8}$ In this method, coefficients are drawn several times from the asymptotic normal distribution of the parameter estimates; fare equivalents are calculated for each of these draws (Krinsky and Robb, 1986). The method is less computationally burdensome than bootstrapping (Carlsson et al., 2003).
} 
(2011) in Tigray, northern Ethiopia, suggested large welfare effects; area enclosures yielded significant net present value (NPV), even when the opportunity cost of alternative land use was considered. ${ }^{9}$ Moreover, qualitative studies have revealed that farmers in different parts of Ethiopia positively perceive area enclosures, feeling that area enclosures will benefit them (Shylendra, 2002; Tefera et al., 2005 and Mekuria et al., 2011). Although the preceding research does not analyze the welfare effects of area enclosures relative to alternative community forestry attributes, their conclusions are in line with our finding that area enclosures are perceived to provide extensive benefits to our study's participants.

\subsection{Choice Elasticities}

In addition to WTP results, another useful comparison across models is the estimated choice (share) elasticity (Greene and Hensher, 2003). Table 4 presents the implied elasticities calculated from the CL, RPL and LCM models for both the cost and harvest quota attributes. The direct elasticity represents the relationship between a percentage change in the attribute level and the percentage change in the proportion (share) of choices for an alternative, in which the level of the attribute has been changed. In particular, the numbers in the column headed CL imply that a one percent increase in the cost of community plantation in alternative one leads to a 0.150 percent reduction in the proportion of those choosing this alternative. Likewise, a one percent increase in the community plantation harvest quota in alternative one leads to a 0.099 percent increase in the proportion of those choosing this alternative. Similar interpretations can be drawn for the rest of the figures in the table.

As with the rest of the results discussed so far, these elasticities differ across the models considered, as did the reported parameter estimates and average WTP estimates. Given the smaller and more precise WTP estimates, it is not surprising that the share response estimates for the LCM are less sensitive, when compared to the CL and RPL estimates. However, in all of the reported results, the absolute value of the estimated elasticity increases when comparing alternative one to alternative two,

\footnotetext{
${ }^{9}$ Babulo (2007) found that area enclosures yielded an NPV of ETB 1,579/ha and ETB 3,089/ha, when the opportunity cost of alternative land use was considered, and, when it was not considered, respectively. The estimates rose to USD 837 (approximately ETB 10,558.76) when the carbon sequestration benefit was also taken into account, when the opportunity cost of alternatives land use was considered (Mekuria et al., 2011).
} 
regardless of the attribute considered. Similarly, as required by economic theory, the estimated elasticity for the cost attribute is negative; an increase in the cost in any alternative reduces the probability of that alternative being chosen. Furthermore, harvest quota elasticities are positive, supporting the a priori expectation that increased harvest quotas are associated with increased preferences for the alternative, much as we might expect of the income elasticity for a normal good.

\subsection{Discussion}

Ethiopia has a long history of initiating and implementing community forestry programs, primarily due to environmental activism that developed in the 1970s (Mekonnen, 2000). However, these experiences have generally been deemed a failure, because of a top-down intervention approach. For example, hillside enclosures and plantations on communal land have been implemented in the past, within food-forwork schemes; however, the management and planning associated with these interventions were made outside of the community. Recently, though, the incumbent Ethiopian government has developed a different approach, emphasizing communitybased resource conservation and management, as part of its rural development policies (Benin et al., 2002). This change has led to efforts stimulating and organizing collective action with regard to the establishment of area enclosures and plantations or woodlots. In many parts of the country, area enclosure development, as well as community woodlot development, has been carried out in a more participatory process. Although local Departments of Agriculture identified the area to be enclosed or planted, the operational rules are formulated through a general meeting of the community members (Gebremedhin et al., 2003 and Fekadu, 2007).

This increase in community participation has led to the need for research into the types of attributes that are preferable to potential community forest participants, which we address here. In a nutshell, the literature on community forestry programs has mainly focused on how uncertainties regarding ownership and access to community forest plantations, market and demographic pressures led to their widespread failure. Many observers contend that the failure to incorporate local valuations of community forests has been a contributing factor to that failure (Gebremedhin et al., 2003). However, designing a community forestry program that maximizes social welfare and raises acceptance within the community has, so far, not 
featured in the discussion. The present study extends that literature by addressing this empirical paucity. Particularly, the application of the CE method has provided additional understanding of the relative household valuations of various attributes, information that is crucial to the design of programs and incentives that are more likely to lead to the successful implementation of such programs, and, hence, yield the greatest welfare benefits for communities. In addition to providing estimates of values of alternative forest programs, this study revealed that the valuation varies across individuals, or at least groups of individuals. Therefore, our results support the claim that one size does not fit all. In other words, targeting community forestry programs towards the community meant to benefit from the program has great potential to improve the efficacy of community forestry programs.

Considering our results within the context of the literature, a number of parallels can be drawn. Specifically, many of the attributes of the proposed community forests offer substantial welfare benefits to our study's participants. In other words, maintaining land use in its initial state is less preferred, and, therefore, reclaiming the land for the purposes of a community forest improves average household welfare. This result provides additional support to the findings made by Mekonnen (2000), Köhlin (2001), Carlsson et al. (2003), Jagger and Pender (2003), Köhlin and Amacher (2005), Babulo (2007) and Mekuria et al. (2011), in which community forestry offers significant welfare benefits. Moreover, the heterogeneity of estimated welfare impacts supports Mekonnen (2000), who finds that community plantation WTP values varied across geographical locations in Ethiopia

Two important forestry policy implications can be drawn from this study. First, a comparison of marginal willingness to pay for attributes contributes to the understanding of the relative importance that respondents hold for them. Second, the results offer insight into the differential impacts of various program interventions, as well as the economic value of such interventions. Knowledge of these differences can be used to improve the design of community plantation alternatives. Focusing on those attributes with higher average welfare impacts will increase the acceptance of the community forestry program in the local community. Given that a wide variety of attribute bundles can be included in various community forestry programs, such programs will have distributional consequences, and these differential impacts can be 
taken into account for equity considerations.

\section{Conclusion}

The research presented here was based on a choice experiment designed to identify the welfare impact of various community plantation attributes, including: harvest quotas, plantation land type (degraded land or productive communal grazing land), plantation tree species (Eucalyptus, multi-purpose, mixed species of Eucalyptus and multi-purpose), area enclosures (protected area) and the contribution that each household would have to make in order to establish and manage the plantation. Individuals were asked to choose their preferred option from a choice set containing the current situation (as described by current levels of attributes) and two potential alternative scenarios with different levels of improvements in environmental quality that would be contained in the community plantation. From the CE survey, estimates of utility function parameters, the average marginal value of the different attributes, and choice elasticities for a particular set of attributes were generated from CL, RPL and LCM models. The results are indicative of significant preference heterogeneity, suggesting that community forestry programs should be designed for the community, in which the program is to be placed.

We found that there are considerable trade-offs between various attributes of community plantations, and that these trade-offs vary across the choices models implemented. In the CL and RPL, all of the choice attributes were associated with increases in average welfare; however, the RPL point estimates were consistently larger. Although all of the attributes raised welfare, welfare gains were highest for the area enclosure attribute, suggesting that area enclosures should be an important feature of community forestry programs in this study area. Furthermore, the productivity of the community plantations, as measured by its harvest quota, and establishing the community plantation on wasteland, rather than on grazing land, were both found to increase the average welfare across the study population, suggesting that productivity improvements are also important features to be included in the design of community forestry programs in the study area.

However, the strength of the CL and RPL results require caveats. In particular, the LCM identified three distinct classes of farmers in the study area, and preferences 
were found to vary significantly across these segments of the study population. Although one segment of the population mirrors the CL and RPL results, the other two segments did not. This finding provides further evidence that, in fact, one size does not fit all, such that local participation in the development of community forestry programs will strongly influence the success of those programs. Despite the heterogeneity observed in the analysis results, some comforting consistencies, with respect to economic theory were also observed. Specifically, increases in the cost of the program reduce the demand for community forestry, while increases in productivity increase the demand for the community forests.

\section{References}

Adamowicz, W., Boxall, P., Williams, M., and Louviere, J.J. (1998). Stated Preference Approaches for Measuring Passive Use Values: Choice Experiments and Contingent Valuation. American Journal of Agricultural Economics 80: 64-75.

Adhikari, B., Di Falco, S., and Lovett, J.C. (2004). Household characteristics and forest dependency: Evidence from common property forest management in Nepal. Ecological Economics 48: 245-257.

Agrawal, A., and Ostrom, E. (2001). Collective action, property right and decentralization in resource use in India and Nepal. Politics and Society 4: 485-514.

Alpizar, F., Carlsson, F., and Martinsson, P. (2001). Using Choice Experiments for Non-Market Valuation. Economic Issues 8: 83-110.

Arifin B., Swallow, B.M., Suyanto S., and Coe, R.D. (2009). Analysis of farmers preference for community forestry contracts in Sumber Jaya watershed, Indonesia. Ecological Economic 68: 2040-2050.

Babulo, B. (2007). Economic valuation and management of common-pool resources: The case of exclosure in the highlands of Tigeray, northern Ethiopia, $\mathrm{PhD}$ Dissertation, Department Landbeheer en-Economie, Katholieke Universitiet, Leuven

Batsell, R.R., and Louviere, J.J. (1991). Experimental choice analysis. Market Letters 2: 199-214.

Benin, S., Pender, J., and Ehui, S. (2002). Policies for sustainable land management in East African highlands. EPTD Workshop paper, No.13 
Boxall, P.C., and Adamowicz, W. (2002). Understanding heterogeneous preference: A latent class approach. Environmental and Resource Economics 23: 421-446.

Brey, B., Riera, P., and Mogas, J. (2007). Estimation of forest values using choice experiment modeling: An application to Spanish forests. Ecological Economics 64: 305-312.

Carlsson, F., Frykblom, P., and Liljenstolpe, C. (2003). Valuing wetland attributes: an application of choice experiments. Ecological Economics 47: 95-103.

Carlsson, F., Köhlin, G., and Mekonnen, A. (2004). Contingent valuation of community plantations in Ethiopia: A look into value elicitation format and intra-household preference variation, Working paper in Economics No.151, Department of Economics, Gothenburg University.

Ezzine de Blas, D., Ruiz-Pérez , M., and Vermeulen, C. (2011). Management conflicts in Cameroonian community forests. Ecology and Society 16(1): 8 URL: http://www.ecologyandsociety.org/vol16/ iss1/art8/

EFAP: Ethiopian Forestry Action Program. (1993). Issues and actions, volume III, Addis Ababa: Ministry of Natural Resources Development and Environmental Protection, Transitional Government of Ethiopia.

Fekadu, T., (2007). Overview of natural resources in Southern Nations, Nationalities and Peoples Regional State (SNNPS) of Ethiopia, Proceedings of Policies to increase forest cover in Ethiopia, Addis Ababa, 18-19 September, pp 92-103, Addis Ababa, Ethiopian Development Research Institute (EDRI)

Ferrini, S. and Scarpa, R. (2007). Designs with a priori information for nonmarket evaluation with choice experiments: A Monte Carlo study. Journal of Environmental Economics and Management 53: 342-363.

Gebremedhin, B., Pender, J., and Tesfay, G. (2003). Community natural resource management: the case of woodlots in Northern Ethiopia. Environment and Development Economics 8: 129-148.

Greene, W.H., and Hensher, D.A. (2003). A latent class model for discrete choice analysis: contrasts with mixed logit. Transportation Research Part B 37: 681698.

Hanley, N., Mourato, S., and Wright. R.E. (2001). Choice Modeling approaches: A superior alternative for environmental valuation? Journal of Economic Surveys 15: 436-462.

Hanley, N., Wright, R., and Adamowicz,W. (1998). Using choice experiment to value the environment. Environment and Resource Economics 11: 413-428. 
Hanemann, W.M. (1984). Welfare evaluations in contingent valuation experiments with discrete responses. American Journal of Agricultural Economics 66: 332- 341 .

Hanemann, W.M., and Kanninen, B. (1996). The statistical analysis of discreteresponse CV data, in Valuing Environmental Preferences: Theory and Practice of the Contingent Valuation Method in the US, EC, and Developing Countries. I.J. Bateman and K.G. Willis (eds), Oxford University Press, Oxford.

Huber, J., and Zwerina, K. (1996). The importance of utility balance in efficient choice designs. Journal of Marketing Research 33: 307-317.

Jagger P.J, and Pender, J. (2003). The role of trees for sustainable management of less-favored lands: the case of eucalyptus in Ethiopia. Forest Policy and Economics 5: 83-95.

Köhlin, G. (2001). Contingent valuation in project planning and evaluation: The case of social forestry in Orissa, India. Environment and Development Economics 6: 237-258.

Köhlin, G., and Amacher, G.S. (2005). Welfare implications of community forest plantations in developing countries: The Orissa Social Forestry Project. American Journal of Agricultural Economics 87: 855-869.

Krinsky, I., and Robb, A. (1986). On approximating the statistical properties of elasticities. Review of Economics and Statistics 68: 715- 719.

Kuhfeld, W. (2001). Multinomial logit, discrete choice modeling. An introduction to designing choice experiments, and collecting, processing and analyzing choice data with SAS. SAS Institute TS-643.

Lancaster, K.J. (1966). A new approach to consumer theory. Journal of Political Economy 74: 132-157.

Larson, M.A., and Ribot, J.C. (2004). Democratic decentralisation through a natural resource Lens: An introduction, The European Journal of Development Research 16: 1-25.

Linde-Rahr, M. (2003). Property rights and deforestation: the choice of fuelwood course in rural Viet Nam. Land Economics 79(2): 217-234.

Louviere J.J. (1991). Experimental choice analysis: introduction and overview. Journal of Business Research 23: 291-297.

McFadden, D. (1974). Conditional logit analysis of qualitative choice behaviour. In: Zarembka, P. (Ed.), Frontiers in Econometrics, Academic Press, New York 
Mekonnen, A. (1999). Rural household biomass fuel production and consumption in Ethiopia: A case study. Journal of Forest Economics 5(1): 69-97.

Mekonnen, A. (2000). Valuation of community forestry in Ethiopia: a contingent valuation study of rural households. Environment and Development Economics 5: 289-308.

Mekuria. W., Veldkamp, E., Tilahun, T., and Olschewski, R. (2011). Economic valuation of land restoration: The case of exclosures established on communal grazing land in Tigeray, Ethiopia. Land Degradation and Development 22(3): 334-344.

Milon, J.W., and Scrogin, D. (2006). Latent preferences and valuation of wetland ecosystem restoration. Ecological Economics 56: 162-175.

Mogas J., Riera, P., and Bernnett, J. (2006). Comparison of contingent valuation and choice modeling with second order interactions. Journal of Forest Economics 12: 5-30.

Mogas, J., Riera, P., and .Brey, R. (2009). Combining contingent valuation and choice experiment: A forestry application in Spain. Environmental and Resources Economics 43: 535-551.

Ostrom,E. (1999). Self-Governance and Forest Resources, Occasional Paper No. 20, CIFOR.

Revelt, D., and Train, K. (1998). Mixed logit with repeated choices: households' choices of appliance efficiency level. Review of Economics and Statistics 80: 647-657.

Richards, M. (1997). Common property resource institutions and forest management in Latin America. Development and Change 28: 95-117

Riera, P., and Mogas, J. (2004). Finding the social value of forests through stated preference methods: A Mediterranean forest valuation exercise, Silva Lusitana 12: $17-34$.

Qin P., Carlsson, F., and Xu, J. (2009). Forestland reform in China: What do the farmers want? A choice experiment on property preferences, Working paper in Economics, No. 370, Department of Economics, Gothenburg University School of Business.

Shylendra, H.S. (2002). Environmental Rehabilitation and Livelihood Impact: Emerging Trends from Ethiopia and Gujarat. Economic and Political Weekly 31: 3286-3292.

Sikor , T. (2005). Analysing community-based forestry: Local, political and agrarian perspectives. Forest Policy and Economics 8: 339- 349 
Swait, J.R. (1994). Structural equation model of latent segmentation and product choice for cross-sectional revealed preference choice data. Journal of Retailing and Consumer Services 1: 77-89.

Tefera, M., Teketay, D., Hulten, H., and Yemshewa, Y. (2005). The role of communities in closed area management in Ethiopia. Mountain Research and Development 25: 44-50.

Train, K. (1998). Recreation demand models with taste differences over people. Land Economics 74(2): 230- 239.

Train, K. (1999). Halton sequences for mixed logit. Working Paper, Department of Economics, University of California, Berkeley.

Wang, X., Bernnett, J., Xie, C., Zhang, Z., and Liang, D. (2007). Estimating nonmarket environmental benefit of conversion of cropland to forest and grassland programs: A choice experiment modeling approach. Ecological Economics, 63: 114-125.

World Bank. (2008). Ethiopian Sustainable Land Management Project Document, Report No: 42927-ET2008, Washington, DC: World Bank. World Bank/Environmental \& Natural Resources Management Sustainable Development Department AFTSN Africa Region. 
Table 1. Descriptive Statistics of Socio-economic Variables

\begin{tabular}{|c|c|c|c|c|c|}
\hline Variable & Description & Mean & S.D. & Min & Max \\
\hline Forest density & Per-hectare biomass per-capita & 0.254 & 0.497 & 0 & 2.96 \\
\hline TLU & Animal holdings in TLUs & 8.64 & 6.529 & 0 & 42.03 \\
\hline Sex of HH head & $=1$ if respondent is male & 0.89 & 0.30 & 0 & 1 \\
\hline Age of $\mathrm{HH}$ head & AGE of household head & 45.43 & 12.74 & 23 & 90 \\
\hline HH size & Household size & 6.48 & 2.42 & 1 & 15 \\
\hline $\begin{array}{l}\text { Education of } \mathrm{HH} \\
\text { head }\end{array}$ & Household head's education in years & 5.50 & 2.94 & 0 & 14 \\
\hline
\end{tabular}


Table 2. Utility Parameter Estimates from CL, RPL and LCM

\begin{tabular}{|c|c|c|c|c|c|c|}
\hline \multirow[t]{2}{*}{ Variables } & \multirow{2}{*}{$\begin{array}{c}\text { Conditional } \\
\text { logit }\end{array}$} & \multicolumn{2}{|c|}{ Random parameter logit } & \multicolumn{3}{|c|}{ Latent class logit } \\
\hline & & Coeff & $\begin{array}{r}\text { Standard } \\
\text { error }\end{array}$ & Class1 & Class2 & Class3 \\
\hline Eucalyptus & $\begin{array}{r}0.5642 * * * \\
(0.120)\end{array}$ & $\begin{array}{r}0.3390 \\
(0.345)\end{array}$ & $\begin{array}{r}2.1750 * \\
(1.434)\end{array}$ & $\begin{array}{r}29.5428 \\
(27.216)\end{array}$ & $\begin{array}{r}-58.6562 * * * \\
(13.611)\end{array}$ & $\begin{array}{r}-1.2962 * * * \\
(0.226)\end{array}$ \\
\hline Multi-purpose tree & $\begin{array}{r}0.7604 * * * \\
(0.1209)\end{array}$ & $\begin{array}{r}0.6655^{* * *} \\
(0.159)\end{array}$ & $\begin{array}{r}0.5926 \\
(0.513)\end{array}$ & $\begin{array}{l}45.0979 \\
(42.539)\end{array}$ & $\begin{array}{r}-46.8906 * * * \\
(10.904)\end{array}$ & $\begin{array}{r}-1.0319 * * * \\
(0.196)\end{array}$ \\
\hline Mixed & $\begin{array}{r}0.4319 * * * \\
(0.164)\end{array}$ & $\begin{array}{r}0.4014 * * * \\
(0.160)\end{array}$ & $\begin{array}{l}0.5924 \\
(0.513)\end{array}$ & $\begin{array}{r}27.3682 \\
(27.90)\end{array}$ & $\begin{array}{c}1.9794 \\
(1.344)\end{array}$ & $\begin{array}{r}0.0620 \\
(0.197)\end{array}$ \\
\hline Area enclosure & $\begin{array}{r}0.7600 * * * \\
(0.125)\end{array}$ & $\begin{array}{r}0.6410 * * * \\
(0.164)\end{array}$ & $\begin{array}{r}1.6280 * * * \\
(0.828)\end{array}$ & $\begin{array}{r}67.7238 \\
(63.733)\end{array}$ & $\begin{array}{r}-5.4242 * * * \\
(1.453)\end{array}$ & $\begin{array}{r}68.6786 \\
(66.603)\end{array}$ \\
\hline Harvesting quota & $\begin{array}{l}0.0042 \\
(0.004)\end{array}$ & $\begin{array}{r}0.0237 * * * \\
(0.005)\end{array}$ & $\begin{array}{l}0.0064 \\
(0.019)\end{array}$ & $\begin{array}{r}1.5523 \\
(1.476)\end{array}$ & $\begin{array}{r}-0.8247^{* * *} \\
(0.191)\end{array}$ & $\begin{array}{r}0.0611^{* * *} \\
(0.007)\end{array}$ \\
\hline Planting place & $\begin{array}{r}0.2663 * * * \\
(0.086)\end{array}$ & $\begin{array}{r}0.4654^{* * *} \\
(0.133)\end{array}$ & $\begin{array}{l}0.0269 \\
(0.222)\end{array}$ & $\begin{array}{r}-0.0228 \\
(1.935)\end{array}$ & $\begin{array}{r}50.9629 * * * \\
(11.465)\end{array}$ & $\begin{array}{r}0.8521 * * * \\
(0.168)\end{array}$ \\
\hline Cost & $\begin{array}{r}-0.0068^{*} \\
(0.004)\end{array}$ & $\begin{array}{r}-0.0050 \\
(0.005)\end{array}$ & & $\begin{array}{r}-0.7981 \\
(0.838)\end{array}$ & $\begin{array}{r}-0.6097 * * * \\
(0.140)\end{array}$ & $\begin{array}{r}-0.0710 * * * \\
(0.006)\end{array}$ \\
\hline Gender & $\begin{array}{r}-0.0557 \\
(0.181)\end{array}$ & $\begin{array}{r}0.1940 * * \\
(0.106)\end{array}$ & & $\begin{array}{r}-6.8327 \\
(5.400)\end{array}$ & $\begin{array}{r}-4.6345^{* *} \\
(1.328)\end{array}$ & $\begin{array}{r}0.5623 * * * \\
(0.138)\end{array}$ \\
\hline Forest density & $\begin{array}{r}-0.1651 \\
(0.097)\end{array}$ & $\begin{array}{r}-0.1717^{*} \\
(0.117)\end{array}$ & & $\begin{array}{r}-0.1466 \\
(1.000)\end{array}$ & $\begin{array}{r}2.2033^{*} \\
(1.195)\end{array}$ & $\begin{array}{r}-0.478 * * * \\
(0.158)\end{array}$ \\
\hline Livestock & $\begin{array}{r}-0.0037 \\
(0.003)\end{array}$ & $\begin{array}{r}-0.0041 \\
(0.004)\end{array}$ & & $\begin{array}{r}-0.1511 \\
(0.144)\end{array}$ & $\begin{array}{r}1.9655^{* * *} \\
(0.449)\end{array}$ & $\begin{array}{r}-0.0130 \\
(0.008)\end{array}$ \\
\hline $\begin{array}{l}\text { Respondent size } \\
\text { Observation size }\end{array}$ & $\begin{array}{r}600 \\
2400\end{array}$ & $\begin{array}{r}600 \\
2400\end{array}$ & & & & \\
\hline Class probability & & & & $\begin{array}{r}0.403^{* * *} \\
(0.017)\end{array}$ & $\begin{array}{r}0.220 * * * \\
(0.022)\end{array}$ & $\begin{array}{r}0.375^{* * *} \\
(0.018)\end{array}$ \\
\hline Log- likelihood & -1575.76 & -1537.58 & & -1489.71 & -1489.71 & -1489.71 \\
\hline
\end{tabular}

Standard error in parentheses, ${ }^{* * *} \mathrm{p}<0.01,{ }^{* *} \mathrm{p}<0.05,{ }^{*} \mathrm{p}<0.1$ 
Table 3: Average Marginal Willingness to Pay for Attributes

\begin{tabular}{|c|c|c|c|c|c|c|}
\hline \multirow[t]{2}{*}{ Attribute } & \multicolumn{2}{|c|}{ Conditional logit } & \multirow{2}{*}{$\begin{array}{r}\text { Random } \\
\text { parameter } \\
\text { logit }\end{array}$} & \multicolumn{3}{|c|}{ Latent class logit } \\
\hline & $\begin{array}{r}\text { Without } \\
\text { covariates }\end{array}$ & $\begin{array}{r}\text { With } \\
\text { covariates }\end{array}$ & & Class1 & Class2 & Class3 \\
\hline Eucalyptus & $\begin{array}{r}168.44 \\
(81.12)\end{array}$ & $\begin{array}{r}82.76 \\
(50.84)\end{array}$ & $\begin{array}{l}190.38 \\
(97.06)\end{array}$ & $\begin{array}{l}37.01 \\
(7.37)\end{array}$ & $\begin{array}{r}-96.19 \\
(7.01)\end{array}$ & $\begin{array}{r}-18.24 \\
(3.79)\end{array}$ \\
\hline $\begin{array}{l}\text { Multi- } \\
\text { purpose tree }\end{array}$ & $\begin{array}{l}189.30 \\
(90.98)\end{array}$ & $\begin{array}{l}111.55 \\
(65.70)\end{array}$ & $\begin{array}{r}206.03 \\
(111.01)\end{array}$ & $\begin{array}{l}56.50 \\
(8.21)\end{array}$ & $\begin{array}{l}-76.9 \\
(6.32)\end{array}$ & $\begin{array}{r}-14.52 \\
(3.25)\end{array}$ \\
\hline Mixed & $\begin{array}{l}178.17 \\
(90.98)\end{array}$ & $\begin{array}{r}63.36 \\
(46.50)\end{array}$ & $\begin{array}{l}204.05 \\
(69.83)\end{array}$ & $\begin{array}{l}34.28 \\
(2.69)\end{array}$ & $\begin{array}{r}3.24 \\
(2.102)\end{array}$ & $\begin{array}{r}0.87 \\
(2.75)\end{array}$ \\
\hline $\begin{array}{l}\text { Area } \\
\text { enclosure }\end{array}$ & $\begin{array}{l}194.97 \\
(95.10)\end{array}$ & $\begin{array}{l}111.68 \\
(64.50)\end{array}$ & $\begin{array}{r}220.04 \\
(107.72)\end{array}$ & $\begin{array}{r}84.84 \\
(13.02)\end{array}$ & $\begin{array}{r}-8.89 \\
(1.703)\end{array}$ & $\begin{array}{r}966.94 \\
(938.25)\end{array}$ \\
\hline $\begin{array}{l}\text { Harvesting } \\
\text { quota }\end{array}$ & $\begin{array}{r}1.46 \\
(0.82)\end{array}$ & $\begin{array}{l}0.624 \\
(0.84)\end{array}$ & $\begin{array}{r}1.83 \\
(3.72)\end{array}$ & $\begin{array}{r}1.94 \\
(0.25)\end{array}$ & $\begin{array}{r}-1.35 \\
(0.133)\end{array}$ & $\begin{array}{r}0.86 \\
(0.10)\end{array}$ \\
\hline $\begin{array}{l}\text { Planting } \\
\text { place }\end{array}$ & $\begin{array}{r}26.56 \\
(11.40)\end{array}$ & $\begin{array}{r}39.06 \\
(31.16)\end{array}$ & $\begin{array}{r}21.8154 \\
(59.31)\end{array}$ & $\begin{array}{r}-0.028 \\
(2.44)\end{array}$ & $\begin{array}{l}83.57 \\
(4.30)\end{array}$ & $\begin{array}{l}11.99 \\
(1.59)\end{array}$ \\
\hline
\end{tabular}

Standard errors in parenthesis 
Table 4. Implied Direct Share Elasticities

\begin{tabular}{lrrr}
\hline Alternative & $\mathrm{CL}$ & $\mathrm{RPL}$ & $\mathrm{LCM}$ \\
\hline (i) cost & & & \\
1 & -0.150 & -0.138 & -0.088 \\
& $(0.10)$ & $(0.13)$ & $(0.09)$ \\
2 & -0.152 & -0.145 & -0.103 \\
& $(0.09)$ & $(0.10)$ & $(0.08)$ \\
(ii) harvest quota & & & \\
1 & 0.0999 & 0.119 & 0.059 \\
& $(0.07)$ & $(0.11)$ & $(0.13)$ \\
2 & 0.109 & 0.133 & 0.071 \\
& $(0.06)$ & $(0.09)$ & $(0.15)$ \\
\hline
\end{tabular}

Standard deviations in parenthesis 


\section{Appendix A: Attributes and Levels Used in the Choice Experiment}

\begin{tabular}{|l|l|l|}
\hline Attribute & Description & Levels \\
\hline Cost & $\begin{array}{l}\text { The total cost for the individual if } \\
\text { the alternative was chosen }\end{array}$ & Br/year 0, 30, 48, 62 \\
\hline Forest type & $\begin{array}{l}\text { The forest program can } \\
\text { have single tree species, } \\
\text { multipurpose species, a mix } \\
\text { of both or a combination of } \\
\text { herbaceous and wood } \\
\text { species }\end{array}$ & $\begin{array}{l}\text { eucalyptus only, multipurpose } \\
\text { tree only, mix of eucalyptus } \\
\text { and multipurpose tree, area } \\
\text { enclosure }\end{array}$ \\
\hline Type of place & $\begin{array}{l}\text { Describes the quality(degraded or } \\
\text { not) of a place where the } \\
\text { community plantation is to be } \\
\text { planted }\end{array}$ & $\begin{array}{l}\text { Waste land(communal), } \\
\text { productive communal grazing }\end{array}$ \\
\hline Harvesting quota & $\begin{array}{l}\text { The amount of wood biomass that } \\
\text { a household would be allowed to } \\
\text { harvest per year from the } \\
\text { community forest }\end{array}$ & 0, 15load/year, 30load/year \\
\hline
\end{tabular}

\section{Appendix B: Example Choice Set}

\begin{tabular}{|c|c|c|c|}
\hline $\begin{array}{l}\text { Forest } \\
\text { Attributes: }\end{array}$ & $\begin{array}{c}\text { Alternative } 1 \\
\text { (Current } \\
\text { state) }\end{array}$ & Alternative 2 & Alternative 3 \\
\hline Forest type & Same as today & Area closure & Multi-purpose forest \\
\hline Harvest Quota & Same as today & 15 load & 30 load \\
\hline Type of Place & Same as today & Degraded land & Grazing land \\
\hline $\begin{array}{l}\text { Total cost per } \\
\text { household }\end{array}$ & Zero & 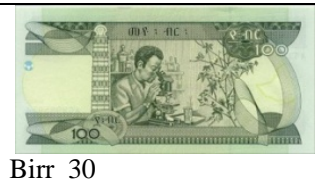 & 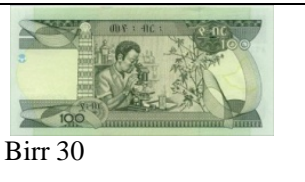 \\
\hline $\begin{array}{l}\text { Indicate the } \\
\text { option you } \\
\text { prefer most } \\
\text { (Tick one) }\end{array}$ & & & \\
\hline
\end{tabular}


Appendix Table C.1. Correlation Matrix for Random Parameters from RPL

\begin{tabular}{|l|c|c|c|c|c|c|}
\hline & Eucalyptus & $\begin{array}{c}\text { Harvest } \\
\text { quota }\end{array}$ & $\begin{array}{c}\text { Planting } \\
\text { place }\end{array}$ & $\begin{array}{c}\text { Area } \\
\text { enclosure }\end{array}$ & $\begin{array}{c}\text { Multi-purpose } \\
\text { tree }\end{array}$ & $\begin{array}{c}\text { Mixed } \\
\text { species }\end{array}$ \\
\hline Eucalyptus $\beta_{1}$ & 1 & $\beta_{2}$ & $\beta_{3}$ & $\beta_{4}$ & & \\
\hline Harvest quota $\beta_{2}$ & -0.942 & 1 & & & & \\
\hline Planting place $\beta_{3}$ & -0.187 & 0.223 & 1 & & & \\
\hline Area enclosure $\beta_{4}$ & 0.824 & -0.708 & 0.386 & & & \\
\hline Multi-purpose tree $\beta_{5}$ & 0.291 & -0.416 & 0.522 & 0.496 & & 1 \\
\hline Mixed species $\beta_{6}$ & 0.088 & 0.086 & 0.894 & 0.721 & 0.643 & 1 \\
\hline
\end{tabular}

